\title{
Nem só de Debates Epistemológicos Vive o Pesquisador em Administração: Alguns apontamentos sobre disputas entre paradigmas e campo científico
}

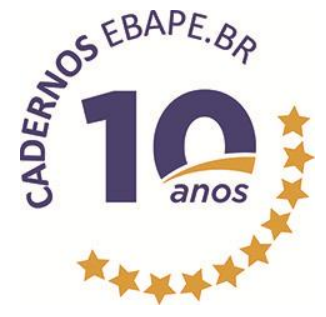

\author{
Not only of Epistemological Debates the Researcher in Administration Lives: Some notes \\ about disputes between paradigms and scientific field
}

\author{
Milka Alves Correia Barbosa ${ }^{1}$ \\ Jouberte Maria Leandro dos Santos ${ }^{2}$ \\ Fátima Regina Ney Matos ${ }^{3}$ \\ Ana Márcia Batista Almeida ${ }^{4}$
}

\section{Resumo}

A discussão sobre abordagens paradigmáticas no campo da Administração pode ser profícua quando provoca os pesquisadores a refletir sobre premissas, práticas e valores compartilhados por uma comunidade científica. Entretanto, ao extremo, torna-se uma disputa que impede a busca de outras abordagens para lidar com a complexidade dos fenômenos sociais. Nesse sentido, importa compreender que, na produção do conhecimento científico, os pesquisadores não se deparam somente com escolhas acerca de epistemologia, de lógica ou de teoria linguística, mas, também, com problemas de política. Este ensaio objetiva contribuir com reflexões sobre o pesquisador e os desafios epistemológicos e políticos com os quais se depara no fazer pesquisa, argumentando que não se trata somente de uma escolha entre positivismos e interpretativismos, mas igualmente envolve disputas de poder dentro de um campo científico). Para tanto, foram selecionados intencionalmente textos com conceitos-chave, como paradigmas e campo científico. Em resposta ao objetivo geral deste ensaio, consideramos que o fazer ciência constitui uma atividade humana que possui vínculo indissociável com espaço e tempo e imbrica-se com jogos de poder. Entendemos, ainda, que o campo científico da Administração no Brasil é um espaço de competitividade e lutas políticas do qual fazemos parte, quer seja como opressores ou privilegiados, mas nunca como meros expectadores. Nessa arena, nem só de debates epistemológicos vive o pesquisador em Administração.

Palavras-chave: Epistemologia da ciência. Paradigma. Campo científico. Pesquisa em administração.

Artigo submetido em 17 de abril de 2013 e aceito para publicação em 18 de novembro de 2013.

${ }^{1}$ Doutoranda em Administração da Universidade Federal de Pernambuco/PROPAD; Professora da Universidade Federal do Vale do São Francisco - UNIVASF. Endereço: Av. José de Sá de Maniçoba, S/N, Centro, CEP 56304 -917, Petrolina - PE, Brasil. E-mail: milka.barbosa@univasf.edu.br

2 Doutoranda em Administração da Universidade Federal de Pernambuco/PROPAD. Endereço: Estrada de Belém, 547, Campo Grande, CEP 50740-320, Recife - PE, Brasil. E-mail: joubertemaria@gmail.com

${ }^{3}$ Doutora em Administração da Universidade Federal de Pernambuco/PROPAD; Professora adjunta do Programa de Pós Graduação em Administração Universidade de Fortaleza - UNIFOR. Endereço: Avenida Washington Soares, 1321, Edson Queiroz, CEP 60811341, Fortaleza - CE, Brasil. E-mail: fneymatos@unifor.br

${ }^{4}$ Doutoranda em Administração pelo PPGA-UFPB; Professora da Universidade Federal de Pernambuco. Endereço: Rodovia BR-104 km 59, Nova Caruaru, CEP 55002-970, Caruaru - PE, Brasil. E-mail: anabatistaalmeida@gmail.com 


\begin{abstract}
The discussion about paradigmatic approaches in the field of Administration may be fruitful when it induces researchers to think through premises, practices, and values shared by a scientific community. However, at the extreme, it becomes a dispute that prevents the search for other approaches to deal with the complexity of social phenomena. In this sense, it is worth understanding that, when producing scientific knowledge, researchers are not faced only with choices about epistemology, logic, or linguistic theory, but also political problems. This essay aims to contribute with reflections on the researcher and the epistemological and political challenges with which he is faced when conducting research, arguing that it is not only a choice between kinds of positivism and interpretivism, but it also involves power struggles within a scientific field. For this, we intentionally selected texts with key concepts, such as paradigms and scientific field. As a response to the general objective of this essay, we think that the making of science constitutes a human activity that has an inseparable link with space and time and it imbricates with power games. We also think that the scientific field of Administration in Brazil is a space of competitiveness and political struggles where we are parties, either as oppressing or privileged individuals, but never as mere spectators. In this arena, not only of epistemological debates the researcher in Administration lives.
\end{abstract}

Keywords: Epistemology of science. Paradigm. Scientific field. Research in administration.

\title{
Introdução
}

A discussão sobre abordagens epistemológicas tem permeado os debates entre os pesquisadores do campo da Administração. É lugar-comum encontrar pesquisadores em conversas acaloradas defendendo o que entendem ser a forma mais adequada de produzir conhecimento em determinada área de estudo.

Não há uma forma única de produzir conhecimento, não há uma explicação única para um fenômeno social, não há uma forma única de interpretar dados, assim como também não há verdade única e inquestionável. O mesmo fenômeno pode ser compreendido a partir de diferentes abordagens epistemológicas e cada uma delas levará a um ponto de chegada diferente. Então, por que insistir na disputa entre um paradigma e outro? Quais são as dificuldades para aceitar que a forma de um pesquisador abordar um tema pode ser diferente a partir da perspectiva paradigmática escolhida por ele?

Esses questionamentos merecem reflexões. Um ponto crucial nessa discussão é que a produção de conhecimento não se trata "apenas" de um embate imparcial de ideias sobre pressupostos epistemológicos, metodológicos e ontológicos. Trata-se, também, de assumir posicionamentos políticos dentro de um campo científico (BOURDIEU, 2004a).

Inicia-se retomando o conceito de paradigma de Kuhn (2001) - um conjunto de crenças, valores e técnicas compartilhadas por membros de determinada comunidade científica - para esclarecer que, ao ser aceito pela maioria da comunidade científica, ele torna-se referência obrigatória e hegemônica para abordagens de pesquisa dentro de uma área de conhecimento. De fato, os paradigmas são fundamentados nas necessidades de compartilhamento e transmissão de conhecimento de sujeitos que pertencem à mesma comunidade científica e revelam opções ontológicas, epistemológicas, axiológicas e metodológicas de determinado grupo de pesquisadores (KUHN, 2001).

Assim, a opção do pesquisador por uma abordagem paradigmática desdobra-se nas teorias que nela se abrigam, na metodologia a ser adotada e na possibilidade de diálogos com outras teorias. Dessa forma, ao escolher uma abordagem paradigmática, o pesquisador não o faz de forma neutra, isso porque, segundo Weber (2003), não existe qualquer análise puramente objetiva da vida cultural, uma vez que não se consegue independência das perspectivas parciais, visto que estas estão presentes no próprio processo de escolha do objeto da pesquisa em Ciências Sociais. 
Para Morin (1998) um paradigma controla não somente as teorias, os raciocínios, mas também o campo cognitivo, intelectual e cultural, de onde as teorias e raciocínios nascem; controla a epistemologia, que controla a teoria e a prática dela decorrente. Assim, se, por um lado, os paradigmas norteiam a produção de conhecimento em determinada comunidade científica, por outro, eles têm efeitos colaterais negativos, como, por exemplo, a imposição de limites cognitivos para os pesquisadores e para a produção científica, mantendo-os sempre dentro de determinadas fronteiras paradigmáticas.

No entanto, na produção de conhecimento científico, os pesquisadores não se deparam somente com escolhas acerca de epistemologia, de lógica ou de teoria linguística, mas se defrontam, ainda, com problemas de política. Em outras palavras: o pesquisador está inserido em um campo onde ocorrem lutas de poder entre indivíduos e grupos com opções axiológicas, ontológicas e epistemológicas, hipóteses e agendas de pesquisa distintas, e isso também o influencia (BOURDIEU, 2004a; 2004b; CLEGG e HARDY, 2010).

O objetivo deste ensaio é contribuir com reflexões sobre o pesquisador e os desafios epistemológicos e políticos com os quais se depara no fazer ciência, argumentando que não se trata somente de uma escolha entre positivismos e interpretativismos, visto que também envolve disputas de poder dentro de um campo científico. Nesse sentido, vale a pena resgatar alguns aspectos da guerra de paradigmas, do conceito de campo científico, para discutir o cerne da questão ora proposta.

\section{Entre Positivismos e Interpretativismos}

A origem da Administração deu-se no campo prático sob a égide do paradigma positivista-funcionalista (OTTOBONI, 2009). Talvez isso explique o fato de que na comunidade científica da Administração no Brasil o positivismo ainda é forte e, para muitos pesquisadores, parece não haver outra forma de fazer ciência (TEIXEIRA e NASCIMENTO, 2001; LIMA, 2011).

O paradigma positivista surgiu em meados do século XIX, com Auguste Comte, junto com a concepção de que conhecer significa mensurar e quantificar. Sua proposta era de que "os fatos só são conhecíveis pela experiência e a única válida é a dos sentidos" (COMTE, 1939, p. 11). No decorrer do tempo, a trajetória do positivismo avançou até o século XXI com novas faces, mas conservando em seu cerne a argumentação lógico-experimental e o empirismo. A partir dessas duas dimensões, sob a perspectiva do paradigma positivista, a realidade pode ser totalmente apreendida e compreendida a partir do estudo das relações entre variáveis, utilizando dados objetivamente processados com o apoio de métodos estatísticos que possibilitam elaborar previsões e estabelecer relações causais entre as variáveis-chave (DEMO, 2009).

Nesse sentido, em sua obra Discurso do método, Descartes (2011) argumenta que analisar a realidade implica decompô-la em partes menores para chegar ao total entendimento dela. Para tanto, parte-se do entendimento de que a realidade é um todo estruturado e matematicamente formalizado e, portanto, o lado não previsível e dinâmico da realidade é tratado como algo secundário a ser descartado. Desde então, procedimentos de formalização rigorosamente controlados passaram a ostentar validade universal e ser apreciados e valorizados como critérios obrigatórios para assegurar conhecimento científico de qualidade e com relevância para a sociedade (DEMO, 2011).

Fazendo referência ao campo da pesquisa organizacional, Vizeu (2010, p. 39) mostra que a influência desse paradigma refletiu-se no grande volume de estudos empíricos voltados, principalmente, a testar hipóteses e correlações causais e a consubstanciar o caráter universal da organização formal, tomando-a um tipo de organização humana "com características fundamentais independentes do contexto histórico".

A despeito de sua importância para o conhecimento científico, o positivismo recebe várias críticas. A primeira delas refere-se à insistência em transpor para as Ciências Sociais os procedimentos dominantes nas 
Ciências Naturais: "críticos oriundos das ciências sociais assacam contra esta expectativa a pecha reducionista e ideológica de manutenção da ordem dominante, à medida que, perdendo a verve questionadora do conhecimento rebelde, declara-se como real o que o método capta" (DEMO, 2011, p. 4).

Santos (2005) afirma que a concepção segundo a qual conhecer significa quantificar faz com que as qualidades intrínsecas do objeto sejam desconsideradas. Ou seja, "ao tomar o que é mais mensurável como mais importante, o positivismo mostra-se ditador de dados que na verdade são seletivos, reducionistas e limitados e não expressam a realidade em sua totalidade como prometem" (SANTOS, 2005, p. 27-28). Como consequência, aquilo que o positivismo desqualifica por não ser quantificável pode ser objeto de perda irreparável, uma vez que o procedimento da elaboração formal será mais valorizado do que propriamente a produção ou a construção do conhecimento. Nessa lógica de racionalidade instrumental, as Ciências Sociais, em especial a Administração, passam eminentemente a ser tidas como quantificáveis, de modo semelhante ao das Ciências Naturais.

Mais um ponto a ser criticado no paradigma positivista é sua suposta neutralidade. Nesse ponto, pode-se questionar como é possível separar o pesquisador da realidade pesquisada quando esse objeto é o próprio homem. Assim, para Demo (2011) é mais honesto assumir que não captamos a realidade como ela é de fato, mas como conseguimos vê-la, tendo em vista que ela é construída socialmente (BERGER e LUCKMANN, 2004).

Para Vizeu (2010), o pressuposto positivista de que a ciência submete-se a leis universais que regem os fenômenos observáveis, junto com a natureza a-histórica do funcionalismo sociológico, remete à análise de instituições sociais considerando-as como estruturas estáticas e, assim, desconsidera fatores históricocontextuais que se modificam ao longo do tempo.

De fato, o êxito da noção de fazer ciência foi diretamente relacionado a esse paradigma, porém, ao eleger a quantificação e a mensuração como critérios únicos para o rigor e a qualidade do conhecimento científico em Administração corre-se o risco de preferir a formalização em detrimento da relevância social e do pluralismo metodológico. Portanto, quando um pesquisador simplesmente enquadra-se e/ou supervaloriza o molde positivista sem reflexões sobre sua escolha, é bem possível que esteja acomodando-se aos paradigmas dominantes de cientificidade e deixando de conhecer ou buscar alternativas epistemológicas.

Dito de outra forma: ainda que os paradigmas sejam signo fundamental da pertença e das comunidades acadêmicas de prática (DEMO, 2011), dedicar-se cegamente a produzir conhecimento sob a perspectiva de um paradigma dominante implica submeter-se a uma lógica de enquadramento limitante e limitada.

Apesar disso, pesquisas de determinadas áreas da Administração adotam os critérios da quantificação e da mensuração como verdadeiro passaporte para garantir o acesso à elite acadêmica. A exigência de uso de procedimentos estatísticos mais sofisticados tem-se tornado a senha dos eleitos precisamente porque não é perícia comum (DEMO, 2011).

Essa preocupação deve-se ao fato de que o paradigma dominante na área de Administração é o funcionalismo sociológico, o qual propõe leis universais que regem os fenômenos observáveis; busca regularidades e relações causais para explicar e predizer fenômenos no mundo social; transpõe modelos e métodos das Ciências Naturais para o estudo de assuntos humanos; e reproduz historicamente a organização formal por meio de padrões regulares de comportamento organizacional (VIZEU, 2007; 2010). Para Costa, Barros e Martins (2010), tal abordagem deslegitima e destrói a riqueza dos múltiplos olhares, mas apesar disso permanece influenciando fortemente os estudos em Administração refletindo-se, por exemplo, na prática dos pesquisadores em adotarem modelos e teorias administrativas estrangeiras em seus estudos.

Apresentando uma perspectiva ontológica diversa, para a abordagem interpretativista não existe uma realidade de todo objetiva ou subjetiva, pois há uma interação entre as características de determinado 
objetivo e a compreensão que os seres humanos criam, socialmente, a respeito dele. Assim, os significados subjetivos, simbólicos e sociopolíticos têm importância para a forma como os indivíduos constroem sua realidade (SACCOL, 2009).

Essa nova perspectiva trouxe à tona a crise epistemológica do paradigma dominante, na medida em que "o aprofundamento do conhecimento permitiu ver a fragilidade dos pilares em que se funda" (SANTOS, 2000, p. 41). A ideia de que a realidade não é simplesmente a soma das partes e a deficiência do rigor matemático como melhor forma de conhecer o fenômeno deram início à discussão sobre a necessidade de uma nova forma de pensar.

Nessa mesma linha, para Santos (2005), o paradigma dominante entrou em crise por não dar conta dos problemas do mundo globalizado, em permanente transformação. $\mathrm{O}$ avanço da ciência, a complexidade e a incerteza do atual contexto da sociedade demandam um novo modo de pensar ciência, não mais limitado a um único paradigma.

Do ponto de vista desse paradigma, a realidade não é algo dado e posto, esperando ser mensurada. Ao considerar a noção de intencionalidade, a preocupação do interpretativismo não é explicar ou analisar os fenômenos a partir de leis ou relações causais, pois o indivíduo e os fenômenos sociais não respondem a estímulos de forma linear e, dessa forma, não podem ser entendidos a partir de um esquadrinhamento cartesiano. Assim, admite-se que a complexidade emergente da produção de sentido humano e a natureza distinta do mundo social não podem ser entendidas da mesma forma que o mundo natural e físico.

Com isso, é possível considerar a epistemologia interpretativista como sendo construtivista, posto que o conhecimento é construído a partir de interações entre as pessoas dentro de um contexto social. Nesse paradigma, o mundo social é "uma situação ontológica duvidosa" porque "o que se passa como realidade social não existe em qualquer sentido concreto" (MORGAN, 2007, p. 16); é formado pela vivência subjetiva ou intersubjetiva dos indivíduos. Em busca de entender a sociedade a partir do agente da ação estão a hermenêutica, a etnometodologia e o interacionismo simbólico fenomenológico; diferentes vertentes representadas por Burrell e Morgan (1979) como paradigmas alternativos ao positivista-funcionalista e compartilham da premissa da natureza histórica das instituições sociais (VIZEU, 2010).

Cabe, aqui, reconhecer o aumento do interesse pela perspectiva histórica nos estudos em Administração, tanto de pesquisadores brasileiros quanto do exterior, de acordo com Costa, Barros e Martins (2010). Como principais razões que podem estar por trás desse interesse, os autores listam a busca de maior relevância e contribuição teórica das pesquisas por meio da ampliação do uso do método histórico; o resgate dos aspectos históricos e interculturais em oposição à reprodução ideológica dominante, que insiste em excluir o passado ou o contexto das teorias e práticas organizacionais (VIZEU, 2007); e a aproximação dos pesquisadores ao contexto da realidade brasileira, engajando-se e comprometendo-se com sua realidade social (GUERREIRO RAMOS, 1996).

Segundo Vizeu (2007) a incorporação da perspectiva histórica na análise de fenômenos administrativos busca o enriquecimento e a ampliação das pesquisas, quer seja adotando quadro teórico-conceitual constituído a partir da análise histórica ou pela aplicação da pesquisa histórica como método de análise.

Destacando as potencialidades dessa abordagem, Costa, Barros e Martins (2010) afirmam que ao identificar e analisar determinado contexto, por meio de quadro teórico conceitual constituído a partir da perspectiva histórica, o pesquisador pode evitar o caráter a-histórico e determinístico que vem sendo comum em estudos em Administração. Os autores apontam que utilizar conceitos e ideias de uma época para analisar fatos de outro tempo histórico constitui anacronismo, o que provoca distorções metodológicas. Aqui, pode-se vislumbrar um movimento de reação à atemporalidade universal que caracteriza as pesquisas que se apoiam no paradigma positivista dominante. 
Do ponto de vista epistemológico, a perspectiva histórica contesta o caráter a-histórico e determinista do paradigma dominante, na medida em que assume o tempo e o contexto atuais no entendimento do fenômeno em estudo. Metodologicamente, diferentes fontes históricas podem iluminar problemas de pesquisa estudados, "ampliando tanto a noção de objeto de pesquisa quanto a noção de documento" (COSTA, BARROS e MARTINS, 2010, p. 296).

Autores como Vizeu (2007) e Costa, Barros e Martins (2010) concordam que ao adotar a pesquisa histórica como método de análise empírica e analítica revelam-se as relações de poder inerentes à reprodução ideológica dominante que tende a naturalizar o pensar e o agir organizacional. Tal observação corrobora um dos argumentos centrais deste ensaio, qual seja, o entendimento de que teorias e pesquisas são construídas a partir de compromissos ideológicos, políticos, os quais influenciam diretamente a escolha do fenômeno ou objeto de estudo.

Sobre as limitações da abordagem histórica, pode-se apontar que assumir que a construção da realidade se dá por meio de um olhar atribuído de sentido implica admitir que ele varie conforme o pesquisador e suas escolhas políticas de pesquisa. No entanto, vale esclarecer que esse aspecto é visto como limitação em virtude do processo de hegemonização do conhecimento promovido pelo paradigma dominante.

Além dessa limitação, segundo Vizeu (2010, p. 39), é necessário utilizar a metodologia histórica com rigor, de modo a não incidir em erros, como "o universalismo - a concepção do fenômeno organizacional contemporâneo como sendo típico de qualquer organização ao longo da história - e o presentismo - o tratamento descontextualizado dos fenômenos organizacionais".

Para Godoy (1995), pesquisas baseadas na perspectiva interpretativista destacam-se por oferecer possibilidades de estudar os fenômenos que envolvem o homem e suas intricadas relações sociais estabelecidas em ambientes diversos. Nessa abordagem, a realidade ocorre dentro de contextos históricos e é construída socialmente; por isso, as pesquisas sociais e humanas buscam não mais somente o caminho da mensuração, mas o da compreensão (GUBA e LINCOLN, 1994). Com efeito, para o paradigma interpretativista, a compreensão dos fenômenos sociais (e aqui se inserem os da Administração), se dá:

[...] a partir da interpretação das atitudes e do sentido que os agentes conferem às suas ações e para tal é necessário utilizar métodos de investigação e mesmo critérios epistemológicos diferentes dos correntes nas ciências naturais, com vista à obtenção de um conhecimento intersubjetivo, descritivo e compreensivo, em vez de um conhecimento objetivo, explicativo e nomotético (SANTOS, 2005, p. 38).

Isso significa que, sob a perspectiva interpretativista, o pesquisador não impõe categorias analíticas para o estudo empírico de um fenômeno. Ao invés de ir munido de instrumentos e técnicas para mensurar a realidade, muitas vezes, ele elabora seus construtos a partir do trabalho de campo, pois se preocupa em captar aquilo que é mais significativo do ponto de vista das pessoas que estão no contexto pesquisado. Nessa dinâmica, a pesquisa científica depende dos participantes, de suas ideias, palavras, expressões, conceitos e experiências acerca da realidade estudada.

Sob a perspectiva desse paradigma, a Administração pode ser considerada uma ciência que sempre será subjetiva, que:

[...] tem de compreender os fenômenos sociais a partir das atitudes mentais e do sentido que os agentes conferem às suas ações, para o que é necessário utilizar métodos de investigação e mesmo critérios epistemológicos diferentes das correntes das ciências naturais (SANTOS, 2000, p. 64). 
Sabe-se que um paradigma não é melhor que outro, assim como as técnicas e os métodos empregados produzirão conhecimento que ilumina aspectos distintos do fenômeno ou objeto estudado. Assim, os achados da pesquisa norteada pelo paradigma interpretativista mostrarão a realidade a partir de determinados pressupostos diferentes do paradigma positivista. Contudo, quando o pesquisador perde essa noção, ele corre o risco de impô-la como a única e melhor para fazer ciência, o que novamente limita a produção científica a determinada abordagem paradigmática, dessa vez interpretativista. Dentro desse raciocínio, vale a pena ter cuidado para mostrar as limitações do paradigma positivista sem enxergar as críticas ao interpretativismo.

Em se tratando de críticas ao interpretativismo, uma das principais refere-se ao relativismo (SACCOL, 2009). Ao adotar uma posição mais liberal, esse paradigma recai nas normas e práticas comunais restritas de comunidades de pesquisas específicas, o que, para alguns pesquisadores, põe em xeque a cientificidade do conhecimento produzido. Também é comum encontrar argumentos de que as pesquisas que adotam a perspectiva interpretativista são imprecisas, carregadas de subjetividade e manipuláveis.

De fato, a relevância no fazer pesquisa científica não se dá automaticamente pela adoção de um paradigma, seja ele positivista ou interpretativista. A escolha paradigmática por si não é suficiente para garantir rigor, consistência, e qualidade de pesquisa. Se assim fosse, todas as pesquisas positivistas seriam excelentes, assim como as pesquisas construtivistas, mas a realidade não é essa. Há pesquisas boas e ruins, independente do paradigma adotado.

Por isso, pode-se discordar do argumento de Demo (2011, p. 14) de que adotar procedimentos positivistas "quando menos, [...] confere à pesquisa a confiabilidade intersubjetiva, capital acadêmico crucial para os dias de hoje". Adotar procedimentos de mensuração quantitativa quando a pesquisa proposta apoia-se no paradigma interpretativista pode trazer, dentre outros percalços, problemas de consistência metodológica.

Vale, aqui, esclarecer que a ciência pode ser construída de maneiras diversas, desde que com rigor e qualidade acadêmica. Para tanto, é necessário criar espaços, fomentar discussões e fortalecer as propostas alternativas de pesquisa que possibilitem conhecer a realidade social a partir de abordagens paradigmáticas para além da escolha dicotômica entre positivismo ou interpretativismo.

Sobre esse aspecto, especificamente na Administração, discussões, debates e disputas ainda decorrem sobre a "guerra de paradigmas" (CLEGG e HARDY, 2010) a qual se estende aos métodos de pesquisa que atendem às peculiaridades de cada paradigma (LEÃO, MELLO e VIEIRA, 2009). Muitos desses embates decorrem da série de posições epistemológicas e ontológicas definidas por Burrell e Morgan (1979), as quais definem $a$ priori algumas posições metateóricas para o desenvolvimento científico em análise organizacional. Para Caldas (2007, p. 6), "cada um desses quase paradigmas paralelos coexistiria na área e influenciaria teorias que seriam aprisionadas por seus próprios pressupostos e desconheceriam ou ignorariam os demais 'silos' representados por "campos concorrentes"”.

Pautada na incomensurabilidade dos paradigmas e na polarização em torno das dimensões objetivo/subjetivo para classificar a pesquisa, a taxonomia criada por Burrell e Morgan (1979) ainda exerce sua influência no campo da Administração até os dias atuais.

Mais adiante, o estudo de Morgan e Smircich (1980) propõe um continuum em cujos polos situam-se visões antagônicas sobre a natureza das Ciência Sociais: objetiva e subjetiva. Entre os extremos, encontram-se diversas suposições ontológicas e de natureza humana com fronteiras não bem delineadas.

A questão é que, apesar das fronteiras delineadas pelo continuum e as taxonomias de paradigmas, as pesquisas nem sempre se enquadram nas categorias ou polos propostos. Pode-se afirmar que classificações e/ou categorizações induzem o pesquisador a identificar as relações estabelecidas como estanques ou herméticas (COSTA, BARROS e MARTINS, 2010). 
Nesse sentido, no campo da Administração, o caminho do conflito tem sido mais trilhado do que o do consenso, com destaque para as polarizações e antagonismos acirrados entre dois paradigmas e seus pesquisadores - positivistas e interpretativistas, que vão opondo-se em argumentos, seguindo uma previsível escalada de ataques, aumentando a distância de possível conciliação (LIMA, 2011; LEÃO, MELLO e VIEIRA, 2009). "Nesse embate entre as duas tradições, ainda prevalece a visão dicotômica e maniqueísta, a partir da qual só é possível escolher entre dois extremos opostos e mutuamente excludentes" (ROCHAPINTO, FREITAS e MAISONNAVE, 2010, p. 124).

Como consequência, pesquisadores vêm gerando um debate quase dogmático sobre o valor relativo desses paradigmas e alguns deles acabam por desviar sua atenção sobre o que é realmente importante: a qualidade, a consistência, o rigor e a relevância da pesquisa em Administração - independente da abordagem paradigmática escolhida.

Nesse cenário, os trabalhos científicos passam a ser analisados a partir de um olhar ideologicamente enviesado e aqueles que não se enquadram dentro da perspectiva hegemônica dominante correm sério risco de ser rechaçados. Com isso, a produção científica vai se assemelhando a uma grande linha de produção, onde os melhores produtos são aqueles que seguem estritamente os padrões determinados (ALCADIPANI, 2011).

Em poucas palavras: enquanto os pesquisadores continuarem a se preocupar em reafirmar que tal paradigma é superior a outro devido a esta ou aquela característica, pouco contribuirão para a Administração evoluir como ciência, pois estão limitando-se a discutir apenas uma face da atividade científica. Os conflitos científicos não se restringem a argumentos epistemológicos e intelectuais; igualmente, envolvem e estão permeados por interesses de determinado pesquisador ou grupo de pesquisadores, em constituir autoridade (prestígio, reconhecimento, status etc.) dentro de um campo científico. Discute-se a esse respeito na próxima seção.

\section{O Pesquisador em Administração e seu Campo Científico}

Segundo Serva e Pinheiro (2009), o trabalho do pesquisador é influenciado pelas condições sob as quais é produzido; assim, entender esse contexto é iluminar como se chegou ao fruto do trabalho. Nessa perspectiva, estudar o campo científico é intrigante, visto que nesse espaço o pesquisador se defronta com ele mesmo, com seus pares e com seu campo de trabalho e levanta questionamentos sobre sua produção científica e sobre si.

Segundo Demo (1995), a ciência está cercada de ideologia não apenas como elemento do contexto externo, mas que faz parte do próprio processo científico, posto que tentar produzir conhecimento puro, historicamente não contextualizado, é tarefa inócua. Aqui, vale lembrar que tomar a intersubjetividade como critério de demarcação científica revela a preocupação com a opinião dominante da comunidade científica em determinada época e lugar. Ora, se há algo que domina, então, há uma relação de poder; os pesquisadores das Ciências Sociais, especificamente das Ciências Administrativas, têm como se blindar em relação à influência desse fenômeno na produção do conhecimento científico?

Considerando que o poder e a ideologia encontram-se no sujeito e no objeto, a resposta será negativa. Uma vez que a própria realidade social está impregnada de ideologia, visto que é produto histórico do qual fazem parte atores políticos, "não existe história neutra como não existe ator social neutro" (DEMO, 1995, p. 19).

Com seu caráter de invisibilidade, a ideologia é como "uma sombra inevitável do fenômeno do poder, que dela lança mão para se justificar. Poder sagaz não diz que é poder, que deseja dominar, que busca vassalos, que detesta contestação" (DEMO, 1995, p. 19). Muito mais do que se tornar conhecido, o poder manifesta-se sem se identificar, sem dizer a que veio. O poder é cheio de artimanhas, e uma das principais é "imiscuir-se 
entre os homens sem ser percebido, de modo disfarçado e carregado de subterfúgios. Muito mais do que mostrar-se, o poder utiliza disfarces" (MATOS, LIMA e GIESBRECHT, 2011). Segundo Foucault (1987), o sucesso do poder está na proporção daquilo que consegue ocultar. Assim, a ideologia mais inteligente é aquela que se escamoteia na ciência e tem no intelectual uma figura importante na elaboração de argumentos de justificação do poder (DEMO, 1995).

Portanto, sendo o pesquisador um agente da produção científica, um ser social e, por natureza, político, discutir o fazer ciência implica não só refletir sobre escolhas epistemológicas, mas, também, sobre posicionamentos políticos. Para Bourdieu (2004a, p. 34), é inútil tentar separar as determinações científicas puras e as determinações sociais, tendo em vista o imbricamento entre interesses intrínsecos e extrínsecos:

Tudo iria bem no melhor dos mundos científicos possíveis se a lógica da concorrência puramente científica fundada apenas sobre a força de saberes e de argumentos não fosse contrariada e até mesmo, em certos casos, anulada por forças e pressões externas [...]

Ancorado no conceito de poder simbólico, a ideia de campo científico de Bourdieu (1976) surge em oposição à noção de comunidade científica de Kuhn (HOCHMAN, 1994). Para Bourdieu (2004a), a autonomia da comunidade científica, do trabalho científico e da ciência deve ser entendida a partir da natureza da sociedade em que se insere. $\mathrm{O}$ autor questiona a neutralidade da ciência e aponta a necessidade de revelar o que, de fato, está por trás do esforço dito genuinamente desinteressado da comunidade científica kuhniana. "Sai a ciência, entra a sociedade" (HOCHMAN, 1994, p. 209).

O campo científico pode ser compreendido como "campo de forças e um campo de lutas para conservar ou transformar esse campo de forças" e "lugar de relações de forças que implicam tendências imanentes e probabilidades objetivas" (BOURDIEU, 2004a, p. 22). Dentro dele, um produtor ou autor só pode esperar reconhecimento do valor de seus produtos (reputação, prestígio, autoridade, competência) de outros autores que, por também serem competidores, são menos inclinados a concordar ou dar-lhe razão sem debates ou exames. Torna-se, de fato, espaço de lutas (BOURDIEU, 1983).

Sob essa perspectiva, pode-se entender o campo da Administração como um campo científico contendo lutas de poder, monopólios, estratégias, relações de forças, interesses particulares, de lucro etc. Nele ocorrem embates em torno de um tipo específico de capital social: a autoridade científica - que também é o poder de impor uma definição do que seja ciência. Nessa luta, os dominantes são aqueles que impõem a definição de ciência e determinam que "a realização mais perfeita consiste em ter, ser e fazer aquilo que eles têm, são e fazem" (BOURDIEU, 1976, p. 7).

Há, portanto, no campo científico, uma estrutura de relações objetivas entre agentes que define intervenções científicas, lugares de publicação, temas a escolher, objetos de estudo. Por sua vez, essa estrutura resulta da distribuição do capital científico - tipo de capital simbólico que consiste no reconhecimento ou crédito atribuído por pares e concorrentes no interior do campo científico; proporciona autoridade e contribui para definir as regras do jogo, a distribuição dos lucros nesse jogo (BOURDIEU, 2004b).

No campo, duas formas de poder que correspondem a duas espécies de capital científico se fazem presentes. O poder institucional (ou político), relacionado à ocupação de posições importantes em instituições científicas, e o poder específico - decorrente de prestígio pessoal, que repousa no reconhecimento pelos pares. As duas formas de capital seguem leis de acumulação diferentes. O capital social específico (científico puro) é resultado de contribuições reconhecidas ao progresso da ciência. Já o capital científico da instituição vai sendo adquirido por meio de estratégias políticas que exigem tempo para participação em vários eventos, tais como comissões, colóquios, bancas, dentre outros. Ao definir essas duas formas de capital, Bourdieu (2004a, p. 38) caracteriza os pesquisadores pela estrutura de seu capital científico, "ou mais precisamente, pelo peso relativo de seu capital 'puro' e de seu capital 'institucional'”. 
Dando suporte à acumulação desse capital, tem-se a estrutura de distribuição de poder entre os atores em competição que norteia as aspirações científicas, as estratégias e os investimentos em pesquisa. Nas palavras de Bourdieu (1983, p. 34, grifo do autor):

Às diferentes posições no campo científico associam-se representações da ciência, estratégias ideológicas disfarçadas em tomadas de posição epistemológicas através das quais os ocupantes de uma posição determinada visam justificar sua própria posição e as estratégias que eles colocam em ação para mantê-la ou melhorá-la e para desacreditar, ao mesmo tempo, os detentores da posição oposta e suas estratégias.

Vale dizer, os agentes e o volume de seu capital científico determinam a estrutura do campo em proporção ao seu peso. "Cada agente age sob a pressão da estrutura do espaço que se impõe a ele tanto mais brutalmente quanto seu peso relativo seja mais frágil" (BOURDIEU, 2004a, p. 24). Assim, o grupo de pesquisadores com maior capital científico domina o campo e define um conjunto de objetos, questões importantes, em dado momento, sobre os quais os participantes do campo devem se debruçar. Consequentemente, o que é percebido como importante e interessante só tem chance de assim se tornar a partir dos que os outros consideram como tal.

Por essa lógica, quanto mais competidores, menores podem ser as expectativas de lucro; com isso, alguns pesquisadores migram para áreas de conhecimento tidas como menos competitivas, onde podem fazer o mesmo investimento com uma probabilidade maior de retorno. Essa perspectiva igualmente influencia os investimentos realizados pelos pesquisadores com vistas ao lucro obtido em função do capital científico acumulado. Nesse sentido, Bourdieu (1976; 2004a) mostra que as escolhas científicas também são estratégias políticas de investimento e maximização do lucro científico que se transfiguram na aceitação dos pares/concorrentes. O autor reforça que as estratégias no campo científico sustentam-se em dois pressupostos: "i) função puramente científica; ii) função social no campo, ou seja, em relação aos outros agentes envolvidos no campo" (BOURDIEU, 2004b, p. 79).

Tomemos como exemplo dessa lógica o sistema de avaliação da pós-graduação da Coordenação de Aperfeiçoamento de Pessoal de Nível Superior (Capes): ele se pauta em uma (suposta) objetividade para atribuir pontuação aos canais de publicação (editoras, revistas e eventos), enquanto os trabalhos são produzidos por agentes sociais e politicamente situados, que participam de acordos intersubjetivos e negociados em suas práticas do fazer pesquisa e ciência, com vistas a responder à pressão por publicação e acumular capital científico para, assim, continuar e garantir sua posição dentro do campo diante de seus pares e concorrentes.

Por isso, não nos espanta que o aumento da legião de autores na área de Administração seja muito mais que uma questão de esforço de publicação científica relevante. Trata-se, também, de "uma estratégia de autoqualificação e credenciamento curricular dos professores e de legitimação de suas instituições" (MATTOS, 2008, p. 147). Inseridos na mesma lógica, não raro, projetos de pesquisa são desenvolvidos como forma de trazer lucro simbólico mais representativo aos pesquisadores dentro de um contexto de intensa competição.

$\mathrm{Na}$ luta travada no campo científico, dominantes e pretendentes utilizam-se de estratégias antagônicas com estrutura e princípios opostos, pois ocupam posições distintas defendendo seu capital científico. Para aqueles que estão no domínio, estratégias de conservação são adotadas visando a perpetuar a ordem estabelecida. Nesse sentido, Misoczky e Andrade (2005, p. 239) descrevem o campo científico da Administração no Brasil como um "espaço de contradições e de estratégias de preservação e disputa e por uma "censura" que tem sido expressa de modo recorrente". Portanto, quando nos deparamos com alguns pesquisadores lutando para permanecer em cargos em comissões, comitês científicos, por exemplo, é bem provável que estejam buscando manter o status quo de um grupo dentro de um campo e institucionalizar um conceito e uma forma de fazer ciência como únicos ou hegemônicos. 
Do lado dos novatos, é possível que eles ou se conformem ao mainstream ou procurem romper com a lógica dominante propondo uma nova configuração de forças dentro do campo (BOURDIEU, 2004a). Ainda em relação aos novatos, em outras épocas, "o pesquisador publicava seu primeiro artigo muitas vezes após a defesa da dissertação ou tese. Atualmente, na área de Administração, isso ocorre desde a mais tenra fase, isto é, já depois de cursada a primeira disciplina no mestrado ou doutorado" (ROSA, 2008, p. 112). Ou seja, a luta por acumular capital científico e alcançar uma posição dentro do campo vem começando cada vez mais cedo (ALCADIPANI, 2011).

Inserido nessa discussão, o estudo de Misoczky e Andrade (2005) já caracterizava o campo científico da Administração no Brasil pela adoção não reflexiva de modelos advindos de nações dominantes por organizações de ensino e pesquisa, legitimando-os como principais referenciais teóricos e forma de produzir conhecimento. Nessa mesma linha, Rosa (2008) esclarece que as exigências para que uma pesquisa ocupe um lugar na "Big Science", depende de seu alinhamento e submissão aos padrões impostos pelos países centrais, daí o caráter de "colonialidade do saber" (SANTOS, 2005), que delimita desde o referencial teórico, até os temas mais relevantes a ser pesquisados.

Segundo Vizeu (2010), a Administração e as organizações no Brasil só serão devidamente compreendidas quando se buscar entendê-las a partir de suas referências histórico-culturais. Para o autor, apesar de óbvia, a produção acadêmica ainda não reflete "a importância da história local como elemento fundamental na construção da realidade administrativa e organizacional brasileira" (VIZEU, 2010, p. 43). No imaginário de muitos, espera-se que os pesquisadores sejam produtores de conhecimento autônomos e independentes. No entanto, na realidade eles sofrem influências - tanto as inerentes a um campo que está de frente para o mercado, de uma ciência social aplicada, como as pressões por publicação, por exemplo, dos sistemas de avaliação (SERVA e PINHEIRO, 2009). Portanto, o fato das publicações em Administração ainda serem caracterizadas por certa falta de originalidade e ênfase na formalização não ocorre apenas em virtude de razões puramente metodológicas e científicas, mas, também, por que esse campo é heterônomo no Brasil; ou seja, nesse tipo de campo:

[...] a concorrência é imperfeita e é mais lícito para os agentes fazer intervir forças não científicas nas lutas científicas. Ao contrário, quanto mais um campo é autônomo e próximo de uma concorrência pura e perfeita, mais a censura é puramente científica e excluir a intervenção de formas puramente sociais (argumento de autoridade, sanções de carreira etc.) e as pressões sociais assumem a forma de pressões lógicas (BOURDIEU, 2004a, p. 32).

Os aspectos discutidos até o momento sobre a dinâmica do campo científico ajudam-nos a entender e concordar com o posicionamento de Misoczky e Andrade (2005): não podemos temer politizar a academia, já que essa, como campo de poder, é sua natureza, absolutamente politizada. Sendo assim, na luta, as diferenças, as discussões, os contrapontos são salutares para o desenvolvimento da Administração como ciência, enquanto "o consenso não é só difícil, como é impossível e indesejável" (MISOCZKY e ANDRADE, 2005, p. 239).

\section{Apontamentos Finais}

Iniciamos nossas reflexões finais resgatando que Guerreiro Ramos (1981) já defendia a Administração como ciência que necessita refletir sobre suas bases, desenvolver reflexão e crítica sobre seus pressupostos. O caminhar rumo a essa tarefa tem-se mostrado tão difícil quanto necessário. Nele, algumas reflexões mostram-se cruciais.

Começamos assumindo que o pesquisador não é um ser neutro, que escolhe fazer ciência pautando-se apenas em critérios meticulosamente assépticos, objetivos, pensados com precisão milimétrica. Somos, de fato e por 
natureza, seres políticos e fazemos escolhas também a partir de interesses pessoais ou coletivos; na pesquisa científica não nos norteamos somente por opções entre um paradigma ou outro. Somos influenciados por ideias, opiniões, preconceitos, interpretações e intenções, bem como influenciamos os outros. Somos influenciados por relações de força do campo científico no qual estamos inseridos e são essas relações que estabelecem tendências e orientações para produção e reprodução do conhecimento. Como Bourdieu (2004a, p. 28) explica:

Essa arte de antecipar as tendências, observada por toda parte, que está estreitamente ligada a uma origem social e escolar elevada e que permite apossar-se dos bons temas em boa hora, bons lugares de publicação (ou mesmo de exposição) etc. é um dos fatores que determinam as diferenças sociais mais marcantes nas carreiras científicas (e isso é mais manifesto ainda na arte moderna). Esse senso de jogo é, de início, um senso da história do jogo, no sentido do futuro do jogo.

De fato, no campo científico da Administração, as disputas entre pesquisadores estão impregnadas de elementos políticos e científicos, devendo esses dois aspectos ser levados em conta. Reconhecemos que nesse espaço os embates se dão entre agentes assimetricamente dotados de capital científico e, por isso, não se apropriam igualmente do produto do trabalho científico. No entanto, alertamos para o perigo de que tratar somente da dimensão puramente política no fazer ciência é tão limitante quanto considerar exclusivamente os aspectos epistemológicos que permeiam os conflitos científicos.

Posto isso, nossa intenção não foi clamar que a ideologia tome conta da ciência. Isso seria falar em dogma. $\mathrm{Na}$ verdade, nossa intenção foi revisitar os aspectos políticos envolvidos no fazer ciência, reconhecendo-os como dimensões da realidade que envolvem educação, cultura, simbolismo, ideologia, e a quantificação não consegue dar conta de sua complexidade.

Entendemos que ao conhecer a dinâmica do campo científico em que estamos inseridos e as relações de força que se dão em seu interior, teremos a possibilidade de discutir criticamente nossos achados, nos resultados, em nossos pressupostos teóricos, metodológicos, e tecemos reflexões para questionar o controle social e ideológico exercido pelas Ciências Sociais sob o manto de uma suposta neutralidade dos pesquisadores.

Aqui, o ponto não é tentar controlar a ideologia ao modo das Ciências Naturais, insistindo em separar claramente sujeito e objeto. Uma alternativa seria reconhecer criticamente que somos, de modo inevitável, ideológicos e assumir postura de discutibilidade (DEMO, 1995) afastando-nos de posturas fanáticas, dogmáticas. Ou assumir a reflexividade como prática entre os constituintes do campo científico da administração (MISOCZKY e ANDRADE, 2005). Nas duas possibilidades, estaríamos pensando na ampliação do entendimento sobre as Ciências Administrativas, considerando-as igualmente espaço de atuação social. Nele, além de pesquisadores, também somos cidadãos e, como tais, precisamos questionar o papel do conhecimento que estamos produzindo no estabelecimento de políticas sociais, na luta por uma sociedade mais democrática. Reconhecemos que essa tomada de posição passa necessariamente pelo entendimento de que os objetos da ciência cada vez mais têm sido usados na produção e economia, fomentando processos de dominação e potencialização de alguns grupos sociais (HOLANDA, 2011; CHAUÍ, 2005).

Juntos, Guerreiro Ramos (1981) e Tenório (2002) mostram o quanto podemos ser ingênuos e alienados quando não olhamos criticamente para as Ciências Administrativas. De fato, uma das limitações da teoria organizacional é não explicar bem a complexidade da análise e do desenho dos sistemas sociais, em grande parte devido aos alicerces psicológicos e comportamentais nos quais se apoiam (GUERREIRO RAMOS, 1981). Bronzo e Garcia (2000) apontam, ainda, que as orientações epistemológicas e as teorizações formuladas pela Administração refletem uma forma particular de observação dos fatos sociais na esfera da produção e do trabalho, carregada de valores e referências dominantes. 
Nesse mesmo alinhamento, o estudo de Demo (1995) já chamava atenção para o débito social das Ciências Sociais quando apenas os critérios de qualidade formal são tomados como balizadores da produção de conhecimento científico. É quando a formalidade se sobrepõe à importância para a sociedade. O mais crítico, nesse cenário, é que muitos dos pesquisadores em Administração insistem em discutir sobre o que é mais certo, o que é mais definitivo, o mais verdadeiro. Esse tipo de debate é "útil ao cientista, porque lhe é cômodo desconhecer a imbricação com os fins enquanto pode viver à sombra e com a sobra do poder vigente. Sobretudo útil ao poder vigente, que aproveita das Ciências Sociais seu potencial ideológico" (DEMO, 1995, p. 24).

Dessa forma, sob nossa perspectiva, mais do que classificar um campo do conhecimento como ciência ou não, cabe a nós, pesquisadores, refletir sobre o nível do debate crítico nele e suas contribuições à construção de novos saberes, com repercussão na ordem social. Entendemos que urge adotar uma postura científica diferenciada, mais crítica, mais reflexiva, menos intransigente acerca das teorias e abordagens que supomos ser indiscutíveis. Se conseguirmos avançar para além das conformações, é plenamente possível que as discussões tornem-se mais profícuas e plurais no campo da Administração (BARBOSA, NEVES, SANTOS et al., 2013).

Retornamos a Bourdieu (2004a, p. 21) para esclarecer que o campo científico também é um espaço relativamente autônomo e, portanto:

É preciso escapar à alternativa da "ciência pura", totalmente livre de qualquer necessidade social, e da "ciência escrava", sujeita a todas as demandas político-econômica. O campo científico é um mundo social e, como tal, faz imposições, solicitações etc., no entanto, relativamente independente das pressões do mundo social global que o envolve.

Assim, trata-se de ir além de discussões entre paradigmas positivistas ou interpretativistas, pois está em jogo a luta por um campo científico mais autônomo, resistente às forças sociais externas, onde seja possível a divulgação de pesquisa e a troca de conhecimento para modificar a configuração de hegemonia, como nos mostram autores como Tragtenberg (1980), Guerreiro Ramos (1981), Misoczky e Andrade (2005), Misoczky e Goulart (2011), Rosa (2008), Rosa e Alves (2011), Silva, Dourado e Lira (2010), Faria (2012), Alcadipani (2005), entre outros.

Vizeu (2010) traz a boa notícia de que há esforços para o maior comprometimento do meio acadêmico com a contextualização cultural e temporal no entendimento dos fenômenos organizacionais. $\mathrm{O}$ autor reforça que a pesquisa histórica é importante para o avanço do conhecimento no campo dos estudos organizacionais. Essa argumentação se dá a partir dos seguintes aspectos: a superação do viés funcionalista de análise organizacional com o surgimento de abordagens e perspectivas alternativas sobre a realidade social no campo; o movimento da guinada histórica em Ciências Sociais - no qual emergiu o relativismo históricocultural e a aproximação entre historiadores e cientistas sociais, com vistas a superar o universalismo positivista (VIZEU, 2010).

Concordamos com Costa, Barros e Martins (2010) que uma das principais contribuições da perspectiva histórica para os estudos em Administração está em conhecer diferentes realidades que coexistem em determinado tempo e espaço, possibilitando aos pesquisadores uma reflexão sobre seu pensar e agir no mundo. Além disso, os autores mostram que, ao defender a relação entre história e administração, viabilizam-se diferentes alternativas em termos de orientação teórica, priorizando um enfoque narrativo alinhado ao interesse mais amplo de orientações interpretativas e discursivas em oposição ao quadro científico tradicional.

Longe de esgotar as discussões, nossa contribuição buscou reafirmar o entendimento de que o fazer científico envolve uma atividade humana que possui vínculo indissociável com espaço, tempo e imbrica-se com jogos de poder. Nessa perspectiva, seria no mínimo ingênuo não reconhecer a academia como um 
espaço de competitividade, do qual fazemos parte, quer como opressores ou privilegiados, mas nunca como meros expectadores. Nesse espaço, nem só de debates epistemológicos vive o pesquisador em Administração.

\section{Referências}

ALCADIPANI, R. Réplica: a singularização do plural. Revista de Administração Contemporânea, v. 9, n. 1, p. 213222, 2005.

2011.

. Academia e a fábrica de sardinha em lata. Organização \& Sociedade, UFBA, v. 18, n. 54, p. 345-348, abr./jul.

BARBOSA, M. A. C. et al. "Positivismos" versus "interpretativismos": o que a Administração tem a ganhar com esta disputa? Organizações em contexto, v. 9, n. 17, p. 1-29, jan./jun. 2013.

BERGER, P. L.; LUCKMANN, T. A construção social da realidade: tratado de sociologia do conhecimento. 24 . ed. Petrópolis, RJ: Vozes, 2004.

BOURDIEU, P. Le champ scientifique. Actes de Ia Recherche en Sciences Sociales, n. 2/3, p. 88-104, 1976.

. O campo científico. In: ORTIZ, R. (Org.). Pierre Bourdieu: sociologia. São Paulo: Ática, 1983. p. 122-155.

. Os usos sociais da ciência: por uma sociologia clínica do campo científico. São Paulo: Ed. Unesp, $2004 a$.

Para uma sociologia da ciência. Lisboa: Ed. 70, 2004b.

BRONZO, M.; GARCIA, F. C. As bases epistemológicas do pensamento administrativo convencional e a crítica à teoria das organizações. In: RODRIGUEZ, S. B.; CUNHA, M. P. (Org.). Estudos organizacionais: novas perspectivas na administração de empresas (uma coletânea luso-brasileira). São Paulo: Iglu, 2000. 65-89 p.

BURRELL, G.; MORGAN, G. Sociological paradigms and organizational analysis: elements of the sociology of corporate life. London: Heinemann, 1979.

CALDAS, M. P. Paradigmas em estudos organizacionais: uma introdução à série. In: BERTERO, C. O.; CALDAS, M. P. Teoria das organizações. São Paulo: Atlas, 2007. 3-11 p. (RAE Clássicos).

CHAUÍ, M. Convite à filosofia. 13. ed. São Paulo: Ática, 2005.

CLEGG, S.; HARDY, C. Introdução: organização e estudos organizacionais. In: CLEGG, S.; HARDY, C. Handbook de estudos organizacionais. São Paulo: Atlas, 2010. v. 1, p. 23-57.

COMTE, A. Importância da filosofia positivista. Lisboa: Inquérito, 1939.

COSTA, A. S. M; BARROS, D. F.; MARTINS, P. E. M. Perspectiva histórica em administração: novos objetos, novos problemas, novas abordagens. Revista de Administração de Empresas, v. 50, n. 3, p. 288-299, 2010.

DEMO, P. Metodologia científica em ciências sociais. 3. ed. São Paulo: Atlas, 1995.

Metodologia do conhecimento científico. São Paulo: Atlas, 2009.



DESCARTES, R. Discurso do método. São Paulo: Saraiva, 2011. 
FARIA, J. H. Análise crítica das teorias e práticas organizacionais. São Paulo: Atlas, 2007.

FOUCAULT, M. Vigiar e punir. Petrópolis, RJ: Vozes, 1987.

GODOY, A. S. Introdução à pesquisa qualitativa e suas possibilidades. Revista de Administração de Empresas, v. 35 , n. 3, p. 57-63, 1995.

GUBA, E. B.; LINCOLN, Y. S. Paradigmatic controversies contradictions, and emerging confluences. In: DENZIN, N. K.; LINCOLN, Y. S. Handbook of qualitative research. Thousand Oaks, CA: Sage, 1994. 193-215 p.

GUERREIRO RAMOS, A. A nova ciência das organizações: uma reconceituação da riqueza das nações. São Paulo: Ed. FGV, 1981.

A redução sociológica. Rio de Janeiro: Ed. UFRJ, 1996.

HOCHMAN, G. A ciência entre a comunidade e o mercado: leituras de Kuhn, Bourdieu, Latour e Knorr-Cetina. In: PORTOCARRERO, V. (Org.). Filosofia, história e sociologia das ciências. Rio de Janeiro: Ed. Fiocruz, 1994. 199227 p.

HOLANDA, L. A. Resistência e apropriação de práticas do management no organizar de coletivos da cultura popular. 2011. 246 f. Tese (Doutorado em Administração) - Universidade Federal de Pernambuco, Recife, 2011.

KUHN, T. S. A estrutura das revoluções científicas. São Paulo: Perspectiva, 2001.

LEÃO, A. L. M. S.; MELLO, S. B. C.; VIEIRA, R. S. G. O papel da teoria no método de pesquisa em administração. Revista Organizações em Contexto, v. 5, n. 10, p. 1-16, 2009.

LIMA, L. A. A Representação das múltiplas dimensões paradigmáticas no estudo da administração: um ensaio sobre os limites contidos nas defesas paradigmáticas excludentes. Revista de Administração Contemporânea, v. 15, n. 2, p. 198-208, 2011.

MATOS, F. R. N.; LIMA, A. C.; GIESBRECHT, C. M. Estudo observacional das relações de poder no filme $O$ óleo de Lorenzo. Cadernos EBAPE.BR, v. 9, n. 2, p. 438-449, 2011.

MATTOS, P. L. C. Nós e os índices: a propósito da pressão institucional por publicação. Revista de Administração de Empresas, v. 48, n. 2, p. 144-149, 2008.

MISOCZKY, M. C.; ANDRADE, J. A. Tréplica: quem tem medo do fazer acadêmico enquanto práxis? Revista de Administração Contemporânea, v. 9, n. 1, p. 219-225, 2005.

; GOULART, S. Viver as contradições e tornar-se sujeito na produção social de nosso espaço de práticas. Organizações \& Sociedade, v. 18, p. 535-540, 2011.

MORGAN, G. Paradigmas metáforas e resolução de quebra-cabeças na teoria das organizações. In: BERTERO, C. O.; CALDAS, M. P. Teoria das organizações. São Paulo: Atlas, 2007. 12-33 p. (RAE Clássicos). $\overline{500,1980 .}$

; SMIRCICH, L. The case for qualitative research. The Academy of Management Review, v. 5, n. 4, p. 491-

MORIN, E. O método. Porto Alegre: Sulina, 1998.

OTTOBONI, C. Perspectivas de triangulação entre diferentes paradigmas na pesquisa em Administração. In: ENCONTRO NACIONAL DA ASSOCIAÇÃO NACIONAL DE PÓS-GRADUAÇÃO E PESQUISA EM ADMINISTRAÇÃO, 33., 2009, São Paulo. Anais... Rio de Janeiro: ANPAD, 2009. p. 1-16. 
ROCHA-PINTO, S. R.; FREITAS, A. S.; MAISONNAVE, P. R. Métodos Interpretativistas em administração: implicações para pesquisadores. Revista de Administração Faces Journal, v. 9, n. 1, p. 115-127, 2010.

ROSA, A. R. "Nós e os índices": um outro olhar sobre a pressão institucional por publicação. Revista de Administração de Empresas, v. 48, n. 4, p. 108-114, 2008.

; ALVES, M. A. Pode o conhecimento em gestão e organização falar português? Revista de Administração de Empresas, v. 51, n. 3, p. 255-264, 2011.

SACCOL, A. Z. Um retorno ao básico: compreendendo os paradigmas de pesquisa e sua aplicação na pesquisa em Administração. Revista de Administração da UFSM, v. 2, n. 2, p. 259-269, 2009.

SANTOS, B. S. A crítica da razão indolente: contra o desperdício da experiência. São Paulo: Cortez, 2000. v. 1.

Um discurso sobre as ciências. 3. ed. São Paulo: Cortez, 2005.

SERVA, M.; PINHEIRO, D. M. Epistemologia e sociologia da ciência da administração: uma reflexão inicial sobre os estudos do campo no Brasil. In: ENCONTRO NACIONAL DA ASSOCIAÇÃO NACIONAL DE PÓS-GRADUAÇÃO E PESQUISA EM ADMINISTRAÇÃO, 33., 2009, São Paulo. Anais... Rio de Janeiro: ANPAD, 2009. 1-16 p.

SILVA, M. M. M.; DOURADO, D. C. P.; LIRA, R. Resistência e práticas alternativas de gestão: o caso do nascedouro de Peixinhos. In: ENCONTRO DE ESTUDOS MULTIDISCIPLINARES EM CULTURA, 6., 2010, Salvador. Anais... Salvador: UFBA, 2010.

TEIXEIRA, J. C.; NASCIMENTO, M. C. R. Triangulação entre métodos na administração: gerando conversações paradigmáticas ou meras validações convergentes? In: ENCONTRO NACIONAL DA ASSOCIAÇÃO NACIONAL DE PÓS-GRADUAÇÃO E PESQUISA EM ADMINISTRAÇÃO, 35., 2011, Rio de Janeiro. Anais... Rio de Janeiro: ANPAD, 2011. 1-17 p.

TENÓRIO, F. G. Tem razão a administração? Ensaios de teoria organizacional e gestão social. Ijuí, RS: Ed. Unijuí, 2002.

TRAGTENBERG, M. Administração, poder e ideologia. São Paulo: Moraes, 1980.

VIZEU, F. Em algum lugar do passado: contribuições da pesquisa histórica para os estudos organizacionais brasileiros. In: ENCONTRO NACIONAL DA ASSOCIAÇÃO NACIONAL DE PÓS-GRADUAÇÃO E PESQUISA EM ADMINISTRAÇÃO, 31., 2007, Rio de Janeiro. Anais... Rio de Janeiro: ANPAD, 2007. 1-16 p.

Potencialidades da análise histórica nos estudos organizacionais brasileiros. Revista de Administração de Empresas, v. 50, n. 1, p. 36-46, 2010.

WEBER, M. A objetividade do conhecimento nas ciências sociais. In: COHN, G. (Org.). Max Weber: sociologia. 7. ed. São Paulo: Ática, 2003, p. 79-127. 